\title{
The response of agricultural drought to meteorological drought and the influencing factors: A case study in the Wei River Basin, China
}

\author{
Shengzhi Huang ${ }^{\mathrm{a}, *}$, Qiang Huang ${ }^{\mathrm{a}}$, Jianxia Chang ${ }^{\mathrm{a}}$, Guoyong Leng ${ }^{\mathrm{b}}$, Li Xing ${ }^{\mathrm{c}}$ \\ a State Key Laboratory Base of Eco-Hydraulic Engineering in Arid Area, Xi'an University of Technology, Xi'an 710048, China \\ ${ }^{\mathrm{b}}$ Institute of Geographic Sciences and Natural Resources Research, Chinese Academy of Sciences, Beijing 100101, China \\ ${ }^{c}$ Department of Atmospheric and Oceanic Sciences and Laboratory for Climate and Ocean-Atmosphere Studies, School of Physics, Peking University, \\ Beijing 100871, China
}

\section{A R T I C L E I N F O}

\section{Article history:}

Received 6 December 2014

Received in revised form 15 May 2015

Accepted 23 May 2015

Available online 6 June 2015

\section{Keywords:}

Agricultural drought

Meteorological drought

The heuristic segmentation method

Drought propagation

The Budyko hypothesis

The Wei River Basin

\begin{abstract}
A B S T R A C T
It is of importance to investigate the response of agricultural drought to meteorological drought and its influencing factors, which could help better understand drought evolution mechanisms and facilitate agricultural drought monitoring and predictions. As a case study in the Wei River Basin (WRB), China, the heuristic segmentation method was first applied to identify change points of long-term hydrological and metrological conditions for the period of 1960-2007. Then the cross wavelet analysis was utilized to reveal the detailed links between agricultural drought (based on Palmer Drought Severity Index (PDSI)) and meteorological drought (based on Standardized Precipitation Index (SPI)) at the seasonal time scale. The controlling factors governing the agricultural response were then explored through quantitatively examining the corresponding large-scale atmospheric conditions and local-scale land surface characteristics. Results indicate that: (1) the variations of the lag time of agricultural drought in response to meteorological drought is large at the seasonal scale, characterized by fast response in summer and relatively slow response in autumn, and the contrasting response in the time lag is mainly due to the buffering effects of soils; (2) the variations of Arctic Oscillation (AO) was found to have large effects on the lag time, with both positive and negative effects; (3) a negative correlation between the lag time and the parameter $w$ in the Fu' equation within the Budyko framework was found, implying the potential effects of vegetation cover on the drought propagation from meteorological drought to agricultural drought in the WRB.
\end{abstract}

(C) 2015 Elsevier B.V. All rights reserved.

\section{Introduction}

Droughts are defined as an environmental disaster and have drawn increasing attentions from ecologists, environmentalists, meteorologists, hydrologists, geologists as well as agricultural scientists due to their huge impacts on ecology, environment, hydrology and agriculture (Wilhite, 2000; Tallaksen and Van Lanen, 2004; Dai et al., 2004; Mishra and Singh, 2010; Zhang et al., 2012; Mohammad et al., 2014). During the past century, the global climate and environment have experienced a remarkable change, resulting in intensified water cycle and more frequent, pronounced and severe extreme events (e.g., droughts and floods) at the global scale (Kunkel, 2003; Roy and Balling, 2004; Christensen and Christensen, 2004; Beniston and Stephenson, 2004). The frequency of drought

\footnotetext{
* Corresponding author. Tel.: +86 29 82312801; fax: +86 2982312797.

E-mail address: huangshengzhi7788@126.com (S. Huang).
}

is projected to increase under the background of global warming especially in the mid-latitude region (Dai, 2010, 2011). Meanwhile, the demand for water has increased manifold because of the growing population and expanding industrial, agricultural, and energy sectors. Combined, water deficits resulting from the spatial-temporal discrepancy between water supply and demand is expected to become more severe under a warming climate (Huang et al., 2014a). Therefore, it is essential to investigate drought evolution characteristic, and especially the formation and propagation mechanism in a changing environment (Huang et al., 2014a).

Typically, droughts are categorized based on different types of deficits of different hydrological components. For example, meteorological droughts are on the basis of precipitation deficits, agricultural droughts on soil moisture deficits, and hydrological droughts on streamflow deficits (Dracup et al., 1980). In general, meteorological droughts develop and end relatively quickly, while the occurrence of agricultural drought is later than that of meteorological drought. Given the readily available precipitation data 
records worldwide, it is relatively easy to assess meteorological droughts. Hence, investigating the lag time of agricultural droughts in response to meteorological droughts provide us an alternative approach for agricultural droughts monitoring and predictions.

However, few studies (e.g., Pandey and Ramasastri 2001; Wang et al., 2011; Van Loon et al., 2012) were performed toward this purpose. Most of previous studies were conducted with the aid of hydrological models. Through various numerical experiments, previous studies indicated that drought propagation is closely associated with local landscape and local climatic conditions (Van Lanen et al., 2012). Wang et al. (2011) used a hydro-agronomic model to study the propagation from meteorological drought to agricultural and hydrological droughts in central Illinois. Van Loon et al. (2012) applied an ensemble mean of large-scale hydrological models to evaluate drought propagations. Although these models are effective tools for investigating drought propagation or the lag time of agricultural drought response to meteorological drought, they are data demanding and intensive computation. In addition, uncertainties arising from the model structure, parameterizations, meteorological forcing and so on are involved. What's more, various assumptions have to be made through the sensitivity experiments. For example, the background statistics have to be assumed stationary and parameters derived from the specific spatial-temporal scale can be transferred to other ungauged regions and other time periods. Therefore, statistical analysis based on the observations can provide new insights in the investigation of drought evolutions and propagations.

The Standardized Precipitation Index (SPI) is widely utilized throughout the world in drought analysis (e.g., Hayes et al., 1999; Ibrahim et al., 2010). It can monitor both short-term and long-term drought effects and is comparable among different locations due to its probabilistic nature. Importantly, the fundamental advantage of SPI is that it can be computed for a variety of time scales (Mishra and Singh, 2010). That is, the appropriate time scale of SPI is able to reflect the lag time of hydrological response to meteorological variations, and variations of SPI with difference time scales may be linked with the water deficits in different components of hydrological cycle (e.g., soil moisture and streamflow) (e.g., Changnon and Easterling, 1989; Elfatih et al., 1999; Van Lanen et al., 2012). Palmer Drought Severity Index (PDSI) has been widely used to reflect agricultural drought due to its close linkage with soil moisture (Dai et al., 2004; Dai, 2010). It has the advantages that it explains temperature and soil characteristics, and is standardized to be comparable among different climatic zones (Mishra and Singh, 2010). The main disadvantages of PDSI are its inherent time scale which makes it more suitable for assessing agricultural impacts and not so much for hydrological droughts and its unsolid assumptions that all precipitation is rain and that streamflow only occurs after all soil layers have become saturated (Mishra and Singh, 2010). Since PDSI combines the information of precipitation and temperature, it is more comprehensive than SPI in assessing agricultural drought.

Therefore, SPI and PDSI were adopted in this study to characterize meteorological and agricultural droughts, respectively, with the purpose of investigating their links and the lag time of agricultural drought in response to meteorological drought. This is the major objective of the present study. In addition, the cross wavelet transform which is a powerful method in testing proposed correlation between two time series (Hudgins and Huang, 1996) and the Budyko hypothesis was carried out to investigate the influence of large-scale atmospheric circulation and local landscape characteristics on the response of agricultural drought to meteorological drought. Furthermore, how does agricultural drought respond to metrological drought at the seasonal scale still merit further investigations, since agricultural crops are more vulnerable to seasonal below-normal soil moisture conditions (Lobell et al., 2008). This is another primary motivation of this study.
Therefore, the main objectives of this study are: (1) to identify possible change points of PDSI series; (2) to investigate the lag time of agricultural droughts responding to meteorological droughts; (3) to explore the influencing factors (e.g., atmospheric circulations and land surface characteristics) impacting the lag time of agricultural drought in response to meteorological drought in the WRB.

\section{Study area and data}

\subsection{Introduction of the WRB}

The Wei River Basin (WRB), as presented in Fig. 1, is chosen as the study area in this study. It is characterized by abundant precipitation and high temperature in summer, and sparse precipitation and low temperature in winter. The WRB is a typical arid and semiarid region with annual precipitation of $559 \mathrm{~mm}$ in the whole basin. It is located in the edge of the monsoon influencing areas, and is subject to high-frequency drought. Topographically, the elevation increases from the lowest Guanzhong Plain in the southeast and southern portion of the basin to the highest northwest mountainous areas.

It should be noted here that the WRB is an important area for China, especially after the foundation of the Guanzhong-Tianshui Economic Zone, which is a national key economic development zone and has a direct stimulus to the rapid economic development in the whole western areas. However, per acre and per capita possession of river runoff in the basin are only $308 \mathrm{~m}^{3}$ and $174 \mathrm{~m}^{3}$, respectively, which only account for about $9 \%$ and $13 \%$ of the corresponding national average, respectively (Huang et al., 2014a). Thus, the WRB is a severe water shortage region, and its shortage in water resources heavily limit its industrial and agricultural development. In view of the significance of water security in the basin, a further investigation concerning the lag time of agricultural drought responding to meteorological drought and its influencing factors is necessary and important.

\subsection{Datasets}

Meteorological data including daily precipitation, average air temperature, average vapor pressure, average sunshine hours, average wind speed, maximum and minimum air temperature data from 21 meteorological stations in the WRB were collected from the National Climate Center (NCC) of the China Meteorological Administration (CMA) (Fig. 1). Each station has meteorological data record covering from January 1st, 1960 to December 31st, 2007. The calculated PDSI values in the WRB were acquired from the Potsdam institute for Climate Impact Research, which were initially obtained from the Food and Agriculture Organization (FAO) digitized soil map of the world (FAO, 1991). In addition, to characterize the largescale atmospheric conditions, monthly Arctic Oscillation (AO) index covering 1960-2007 were obtained from the NOAA National Climatic Data Center (http://www.ncdc.noaa.gov/teleconnections/ao. php). AO is closely associated with the climate of middle and high latitudes regions (Hudgins and Huang, 1996).

Additionally, daily streamflow data from Zhangjiashan, Linjiacun, and Huaxian hydrological stations were obtained from the Yellow River Conservancy Commission. Each station has streamflow data covering January 1st, 1960-December 31st 2007. Specifically, Zhangjiashan station is located in the middle reaches of the Jinghe River, and its catchment area is approximately $4.2 \times 10^{4} \mathrm{~km}^{2}$. Linjiacun station lies in the upper reaches of the WRB, and its catchment area is approximately $3.3 \times 10^{4} \mathrm{~km}^{2}$. Huaxian station is situated in the downstream of the WRB, and its total catchment area approximately accounts for $97.16 \%$ of the whole 


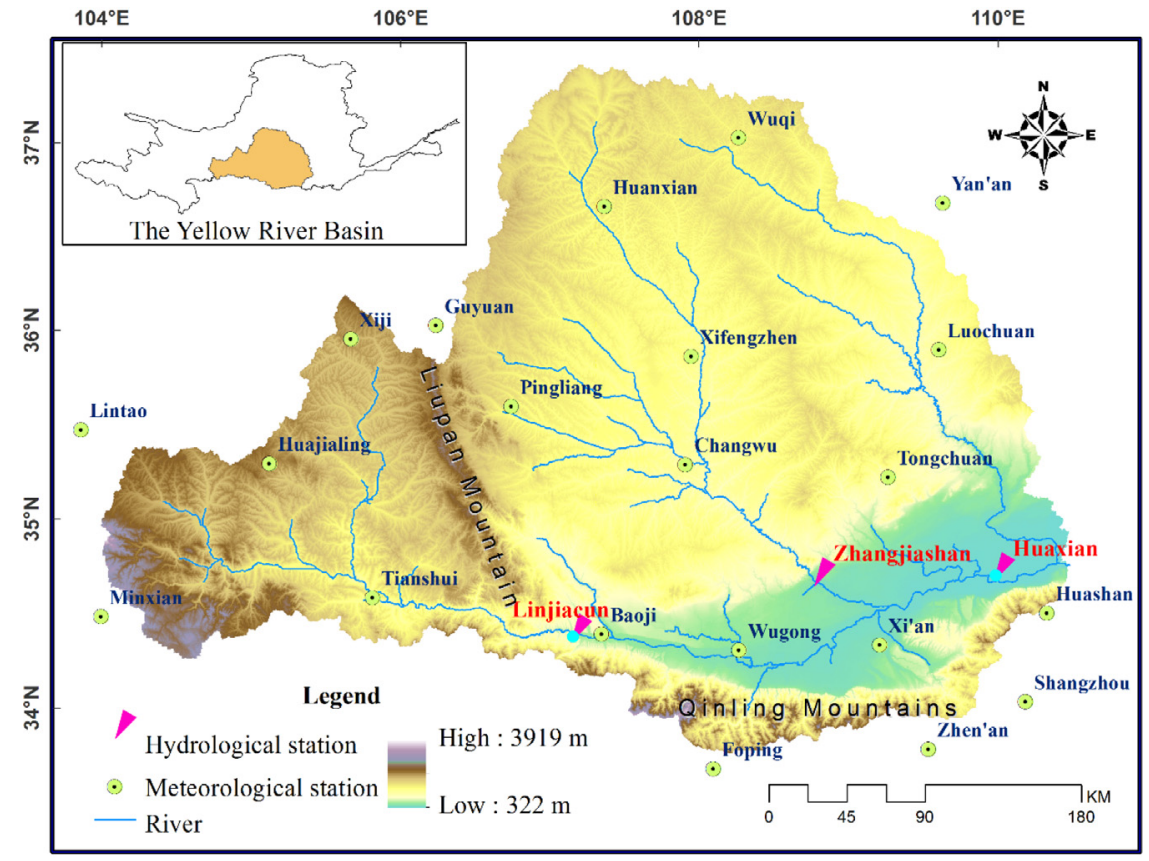

Fig. 1. Location of the Wei River Basin and relevant hydro-meteorological stations in the Yellow River Basin.

basin. Therefore, the runoff records from Huaxian station can be regarded as the streamflow of the whole basin.

\section{Methodologies}

\subsection{The heuristic segmentation method}

Existing statistical test methods such as the Mann-Kendell test, sliding $T$ test, sliding $F$ test, and rank sum test are frequently utilized to identify change point. All of them are based on the assumption of linearity and smoothness. However, hydrological time series exhibits highly nonlinear characteristic due to the high variability of hydrological process. Thus, it is difficult to capture real change point using these approaches. Therefore, the heuristic segmentation method (Pedro et al., 2001) that is based on the thought of sliding $T$ test and modified to identify change point of nonlinear time series was introduced to detect change point of PDSI series in the WRB. For dividing a non-stationary time series into several stationary subseries, a sliding pointer moves step-by-step from left to right along the time series (Pedro et al., 2001). Then, the averages of left and right subseries expressed as $\mu_{1}$ and $\mu_{2}$, respectively, are computed. For two Gaussian-distributed random series, the difference between the averages of the two subseries at a statistical significance (at 95\% significance level) is assessed by the Student's $t$-test statistic expressed as following:

$t=\left|\frac{\mu_{1}-\mu_{2}}{S_{\mathrm{D}}}\right|$

where

$S_{D}=\left(\frac{\left(N_{1}-1\right) s_{1}^{2}+\left(N_{2}-1\right) s_{2}^{2}}{N_{1}+N_{2}-2}\right)^{1 / 2}\left(\frac{1}{N_{1}}+\frac{1}{N_{2}}\right)^{1 / 2}$

denotes the pooled variance, $s_{1}$ and $s_{2}$ are the standard deviations of the two series, $N_{1}$ and $N_{2}$ are the number of data in the two series. By moving the pointer along the specific time series step-by-step, then the statistic $t$ is computed to evaluate the difference between the averages of the left and right time series. A larger $t$ means a more obvious difference between the two time series. The largest $t$ value can be regarded as an ideal candidate for the cut point. Then, the corresponding statistical significance $P\left(t_{\max }\right)$ is calculated. Since the series is not independent and cannot be gained in a closed analytical form, $P\left(t_{\max }\right)$ is not the standard Student's $t$-test, and it is approximately computed as follows:

$P\left(t_{\max }\right) \approx\left\{1-I_{\left[v /\left(v+t_{\max }^{2}\right)\right]}(\delta v, \delta)\right\}^{\eta}$

where $\eta=4.19 \ln N-11.54$, and $\delta=0.4$ is obtained from the Monte Carlo simulations, $N$ is the number of the time series to be cut, $v=N-2$, and $I_{x}(a, b)$ denotes the incomplete beta function. If the difference between the averages is not statistically significant (e.g., $P\left(t_{\max }\right)$ is less than the threshold of 0.95$)$, the time series will be not split. Conversely, the time series will be divided into two segments. If the time series is split, the iteration of the above procedures on each new segment will continue until the gained significant value is less than the threshold or the length of the obtained segments is less than the preset minimum segment length $\left(\ell_{0}\right)$.

\subsection{Standardized Precipitation Index (SPI)}

The SPI was first proposed by McKee et al. (1993) to evaluate the drought conditions in Colorado, which has the ability to monitor precipitation conditions in a long time series and indicate precipitation deficits relative to the climatology of the period. Since the SPI can capture the drought features with different time scales $(1,3,6$, $9,12,24$, and 48 months), it has been broadly applied to analyze different aspects of droughts (Logan et al., 2010). The SPI can monitor short-term water supplies, which is of great importance to water management and agricultural production. Short-term shortage of soil moisture may lead to a greatly adverse influence on agricultural production, thereby triggering an agricultural drought (Mishra and Singh, 2010).

The calculation of SPI is based on a long time precipitation observation data on a given time scale. The long-term precipitation observation data are fitted to a specific probability distribution, which is subsequently transformed to the standard normal distribution (McKee et al., 1993). Firstly, the moving averages of monthly precipitation series from the original precipitation series of a given meteorological station are computed on a specific time scale. Then, 
the gamma probability distribution function is applied to fit the average monthly precipitation series. Ultimately, the SPI value is calculated through transforming the cumulative probabilities of the Gamma distribution to the standard normal distribution (McKee et al., 1993; Kao and Govindaraju, 2010). The detailed SPI calculation formulas can be referenced to previous studies (McKee et al., 1993; Logan et al., 2010; Huang et al., 2014b).

\subsection{Palmer Drought Severity Index (PDSI)}

The PDSI was originally proposed by Palmer (1965) with the purpose of measuring the cumulative departure of surface water balance. It incorporates antecedent and current moisture supply and demands into a hydrologic accounting system, including a twolayer bucket-type model for soil moisture computation. It has been widely used to reflect agricultural drought due to its close link with soil moisture (Guttman et al., 1992; Dai et al., 2004; Dai, 2010). Calculation of PDSI starts with the determination of monthly departure of moisture from normal by evaluating the differences between precipitation and actual precipitation (Dai, 2011). The precipitation can be derived based on the water balances equation, through deducting the expected supply from the expected demand factors to obtain the water demand which must be met by precipitation (Dai, 2011). Then, the monthly moisture anomalies are transformed into the indices of moisture anomaly multiplied by a weighting factor. Finally, wetness or dryness severity is deduced based on moisture anomaly index.

\subsection{The cross wavelet analysis}

The cross wavelet analysis proposed by Hudgins et al. (1993) is a powerful and effective method for testing the linkage between two time series. It is a new technique coupled with the cross spectrum analysis and wavelet transform, and it can preferably reflect the correlation between two time series in the time-frequency domain (Hudgins and Huang, 1996; Torrence and Compo, 1998). The cross wavelet transform of two specific time series $x_{n}$ and $y_{n}$ can be defined as,$W^{\mathrm{XY}}=W^{\mathrm{X}} W^{Y^{*}}$ where ${ }^{*}$ denotes their complex conjugation. The cross wavelet power is expressed as $\left|W^{X Y}\right|$. The complex argument arg $\left(W^{x y}\right)$ can be regarded as the local relative phase between $x_{n}$ and $y_{n}$ in the time-frequency domain. The theoretical distribution of the cross wavelet power of the two time series with their background power spectra $P_{k}^{X}$ and $P_{k}^{Y}$ is expressed as follows (Torrence and Compo, 1998):

$D\left(\frac{\left|W_{n}^{X}(s) W_{n}^{Y *}(s)\right|}{\sigma_{X} \sigma_{Y}}<p\right)=\frac{Z_{v}(p)}{v} \sqrt{P_{k}^{X} P_{k}^{Y}}$ where $Z_{v}(p)$ is the confidence level associated with the probability $p$ for a probability distribution function defined by the square root of the product of two $\chi^{2}$ distributions (Grinsted et al., 2004). The relevant codes of the cross wavelet transform can be downloaded freely in the following website: http://www.pol.ac.uk/home/research/ waveletcoherence/

\subsection{The Budyko hypothesis analysis}

Recently, the Budyko hypothesis has been widely utilized to study basin-scale water and energy balances, and the Fu's equation is one of the formulations of the Budyko curve (Yang et al., 2007; Li et al., 2013). The Budyko hypothesis is an effective tool for investigating the interaction between climate, hydrological cycle, and vegetation (Roderick and Farquhar, 2011; Yang and Yang, 2011). According to $\mathrm{Fu}$ (1981), the relationship between the long-term average annual ET, PET, and $P$ can be expressed as follows:

$\frac{\mathrm{ET}}{P}=1+\frac{\mathrm{PET}}{P}-\left[1+\left(\frac{\mathrm{PET}}{P}\right)^{\omega}\right]^{1 / \omega}$

where $w$ is a model parameter of water available coefficient related to the vegetation type (Fu, 1981). The parameter $w$ is an empirical parameter controlling the shape of the Budyko curve and reflecting the influence of land surface characteristics, which may have a great effect on the lag time of agricultural drought response to meteorological drought. Therefore, the relationship between the lag time and the parameter $w$ of the Fu's equation was analyzed in this study, aiming at revealing the possible impact of land surface characteristics on the lag time.

\section{Results}

\subsection{The change characteristics of the PDSI in the WRB}

The annual PDSI series in the basin above Zhangjiashan and Linjiacun and the whole basin is plotted in Fig. 2. It can be found that the PDSI values in the WRB vary ranging from -3 to 3 , exhibiting a high fluctuation. The fluctuation of PDSI values in the basin above Linjiacun is largest among the three basins. For the three basins, their average annual PDSI before 1993 is approximately -0.2 , whilst that after 1993 is -1 , indicating that the PDSI series in the WRB has a noticeable reduction and local agriculture is prone to drought in recent years, which poses a huge threat to local sustainable development.

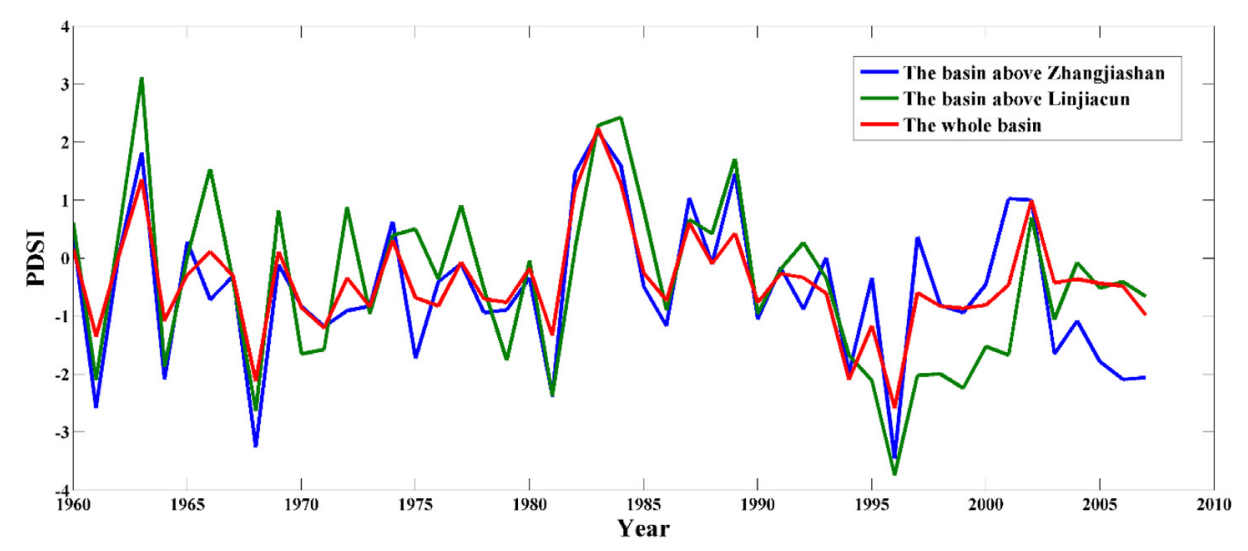

Fig. 2. The annual PDSI series in the basin above Zhangjiashan and Linjiacun and the whole basin. 


\subsection{Identification of possible change points of PDSI series}

The heuristic segmentation method introduced in Section 3.2 was used to identify possible change points of annual runoff and precipitation series at the three stations. The threshold $P_{0}$ was set to 0.95 and $\ell_{0}$ was set to 25 . The segmentations and change points of the PDSI and precipitation series in the three basins are exhibited in Fig. 3.

It can be seen from Fig. $3 \mathrm{~A}$ that no change point of average monthly PDSI series in the basin above Zhangjiashan was identified due to the condition that $P\left(t_{\max }\right)=0.82<P_{0}$. Similarly, no change point of annual precipitation series was detected because of the condition that $P\left(t_{\max }\right)=0.81<P_{0}$. Likewise, with regards to the whole basin, no change point was found in annual PDSI and precipitation series. However, regarding the basin above Linjiacun, one change point (1993) of PDSI series was identified due to the condition that $P\left(t_{\max }\right)=0.97>P_{0}$, whilst no change point of annual precipitation series was found.

\subsection{The lag time of agricultural drought responding to meteorological drought}

The fundamental advantage of SPI is that it can be computed on various time scales, which can be used to monitor short-term and long-term water resources anomalies, thereby being capable of monitoring agricultural and hydrological drought. Thus, the approximate time scale of SPI used to monitor agricultural drought can be regarded as the lag time of hydrological drought responding to meteorological drought. Here, the calculated PDSI values were used to reflect agricultural drought in the WRB due to their ability of reflecting the abnormal conditions of soil moisture. In order to investigate the lag time of agricultural drought responding to meteorological drought, the relationships between PDSI and SPI values with different time scales were analyzed. The correlation coefficients between the monthly PDSI and SPI series with different time scales in the three basins are illustrated in Figs. 4-6, respectively.

It can be easily seen from Fig. 4 that the lag time in the basin above Zhangjiashan has a noticeably seasonal characteristic. High correlation coefficients $(>0.7)$ are concentrated in spring and summer (February-July) with the time scale ranging from 3 to 8 months. The lag time in summer is approximately 3 months, which is relatively shorter than that in other seasons, indicating a fast response to meteorological drought in summer. This may be due to the highfrequency rainfall in this season which leads to high soil moisture in this area, which facilitates the formation of runoff. The response time in spring (nearly 6 months) is longer than that in summer due to the potential effects of snowmelt. Note that most of basin is covered with snow in winter, and most of snow melt occur in next spring. Regarding autumn and winter, the correlations between monthly PDSI and SPI are relatively low, and their lag time is relatively long, primarily as a consequence of the buffering effects of the water stored in the soils during the preceding months.

Similarly, Fig. 5 shows that the lag time of agricultural drought responding to meteorological drought in the basin above Linjiacun has an obviously seasonal characteristic. However, overall, the corresponding correlation coefficients between PDSI and SPI on different time scales in the basin above Linjiacun are slightly smaller than those in the basin above Zhangjiashan. In general, the lag time in this area is shorter than that in the basin above Zhangjiashan. The primary reason may lie in their different topographies. As Fig. 1 exhibits, the slope of the basin above Linjiacun is larger than that of the basin above Zhangjiashan, which is easier to generate runoff after raining and less water recharges to soil, thus leading to a faster response to precipitation deficit.
Regarding the whole basin, the lag time of agricultural drought responding to meteorological drought also has a remarkable seasonal characteristic. The highest correlations were detected in May-July with 3-month SPI, whilst the lowest correlations were found in March-April with 1-month SPI. On the whole, the lag time in the spring, summer, autumn and winter is about $6,3,8$ and 8 months, respectively, in the WRB.

Given the different lag time in different basins, it should be noted here that it is very necessary to consider about the usefulness of SPI with different time scales to monitor drought in specific surface water resources. This finding is consistent with Szalai et al. (2000), who investigated the correlation between scales of SPI and surface water resources, and found a distinct spatial pattern of correlations. Therefore, we emphasize that drought monitoring and predictions based on SPI must select an appropriate timescale as SPI with different timescales does reflect different aspects of water anomalies in the land surface water cycle.

\subsection{The links between agricultural drought and meteorological drought}

Based on the results in Section 4.3, we can conclude that it is essential to consider the usefulness of SPI with various time scales to monitor drought in surface water resources such as agricultural drought. In order to provide detailed evidence for the usefulness of SPI with different time scales and to reveal the detailed links between agricultural drought and meteorological drought, the cross wavelet analysis was employed in this study. As outlined above, the strongest correlations were found in May-July with 3-month SPI, whilst the weakest correlations were found in March-April with 1-month SPI in the WRB. Hence, the average 3-month SPI series in May-July and the average 1-month SPI series in March-April in the WRB were used to analyze their links with the corresponding monthly PDSI series. Based on the Morlet wavelet, the cross wavelet transform between the average 1-month SPI series in March-April and the average 3-month SPI series in May-July and the corresponding monthly PDSI series are shown in Fig. 7A and $B$, respectively.

From Fig. 7A, an anti-phase relationship between the average 1-month SPI series in March-April and the corresponding monthly PDSI series in the WRB is found. Specifically, a statistically significantly anti-phase correlation with 1-4 and 1-6 year period signals is detected during the periods of 1960-1968 and 1990-2007, respectively. In contrast, an in-phase correlation with a 6-8 year period signal is found during 1980-1992. In theory, the relationship between meteorological drought and agricultural drought is expected to be positive. However, the relationship between the average 1-month SPI series in March-April and the corresponding monthly PDSI series in the WRB is primarily negative, which is not reasonable. Therefore, 1-month SPI series cannot be used to monitor agricultural drought in the WRB.

Fig. 7B shows that the average 3-month SPI series in May-July and the corresponding monthly PDSI series have a noticeably inphase correlation at different time scales ranging from 1 to 16 years. The response of agricultural drought to meteorological drought is determined by wide-range atmospheric circulation and local underlying surfaces at different time scales (Medved-Cvikl et al., 2012). Thus, Fig. 7B is more reasonable to reflect the links between agricultural and meteorological droughts, thereby further verifying the usefulness of SPI with different time scales when monitoring agricultural drought. Therefore, 3-month SPI series can be used to monitor agricultural drought in the WRB.

Evaporation plays a key role in the mass and heat fluxes in the global atmospheric system. The large-scale atmospheric system is expected to impact the lag time of agricultural drought response to meteorological drought primarily by means of affecting actual 

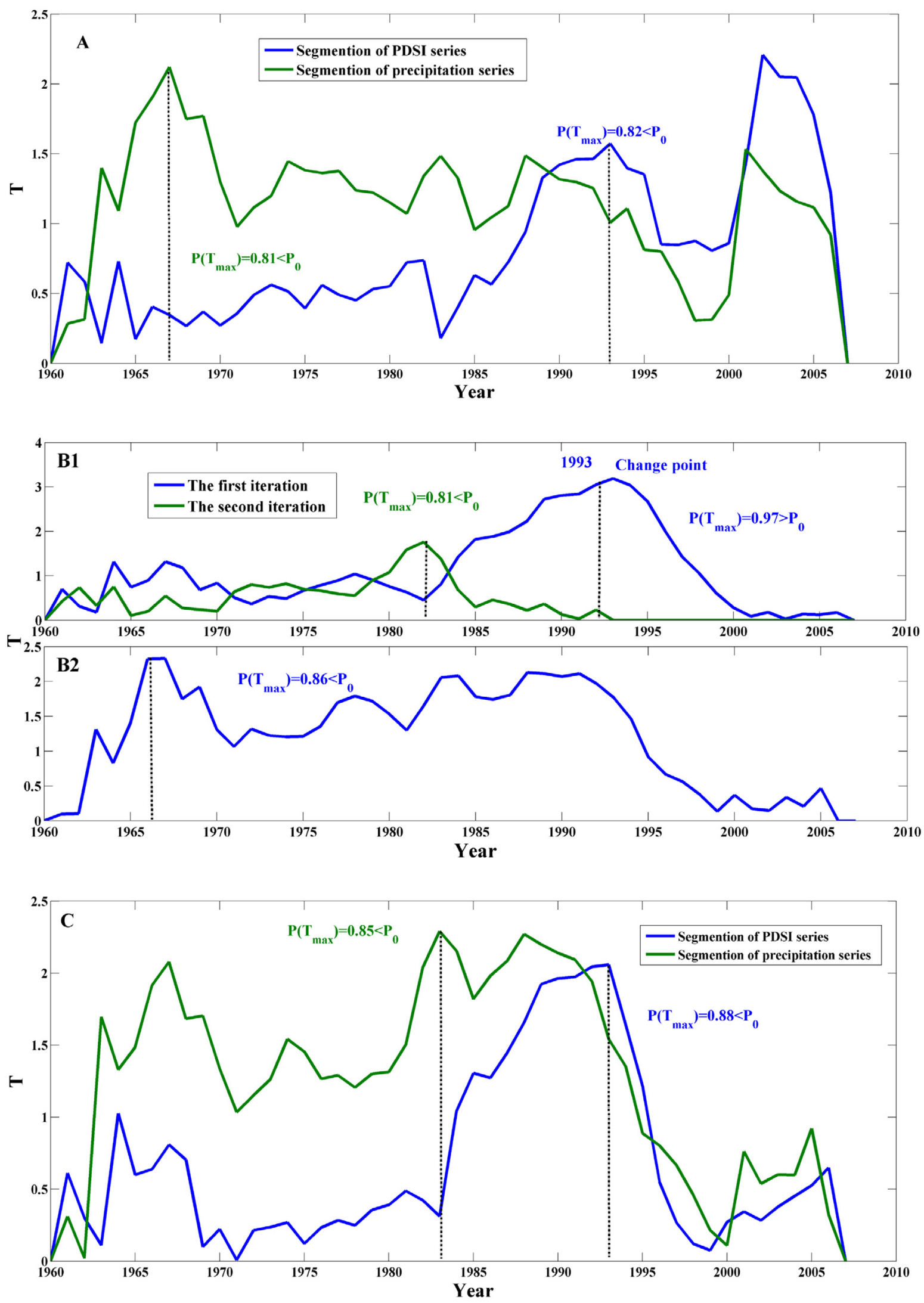

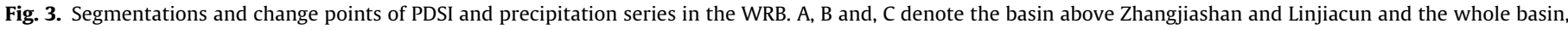
respectively. 


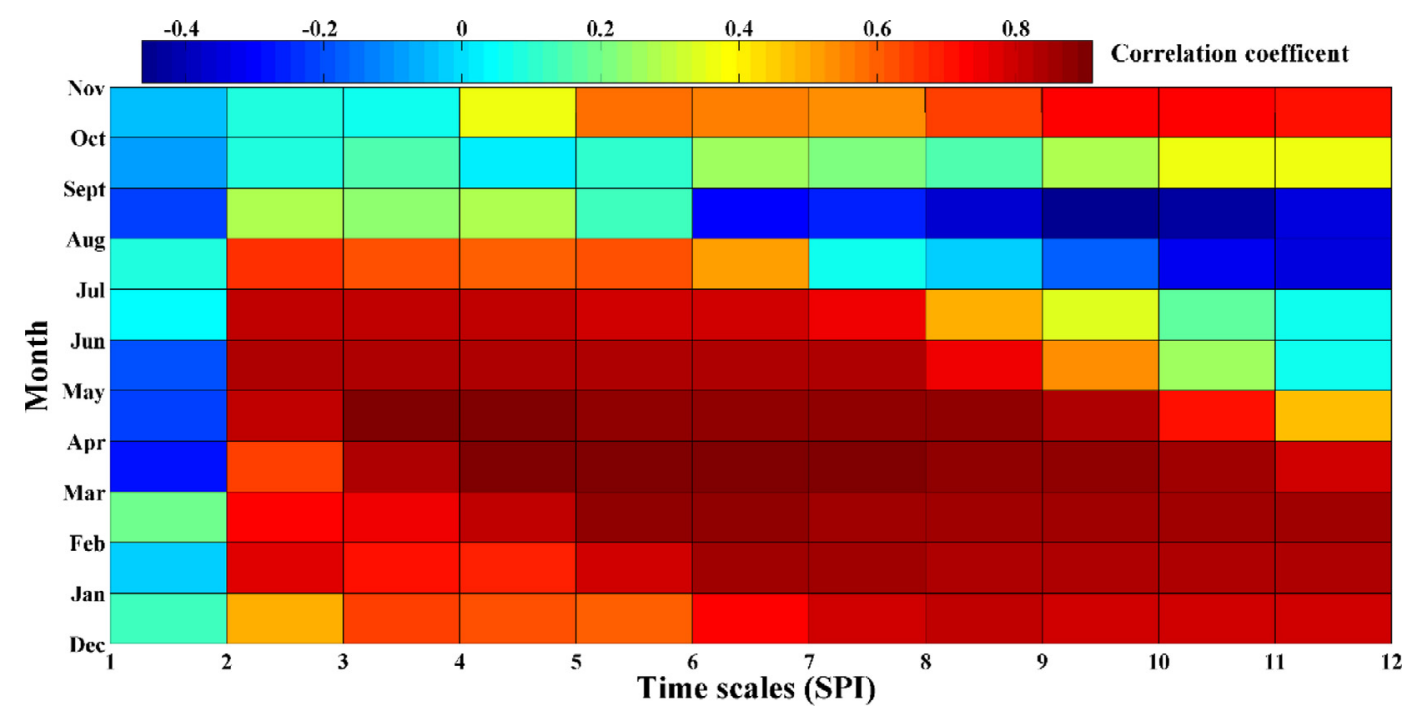

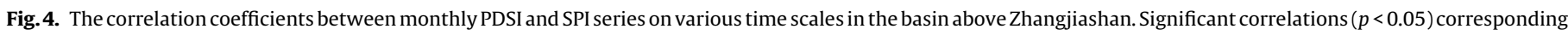
to correlation coefficients values larger than 0.29 .

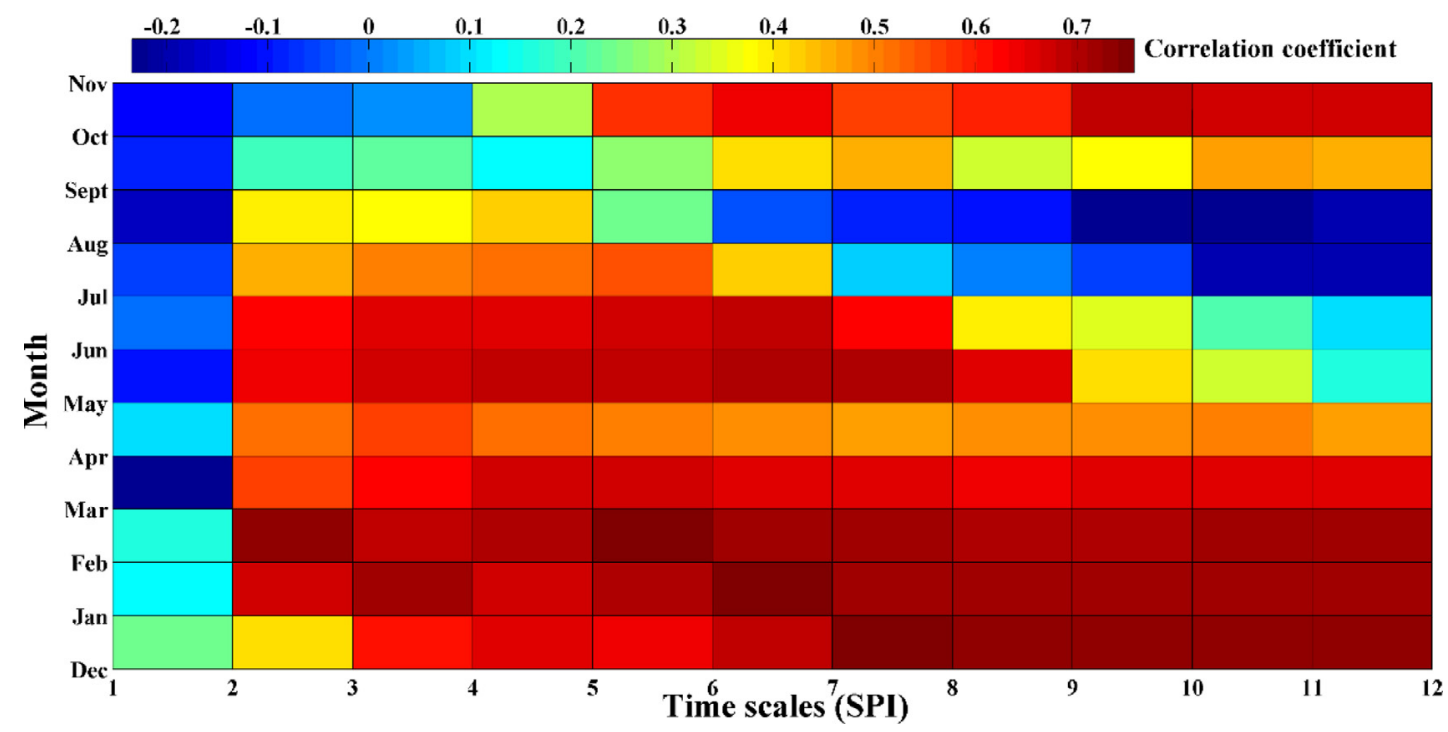

Fig. 5. The correlation coefficients between monthly PDSI and SPI series on various time scales in the basin above Linjiacun.

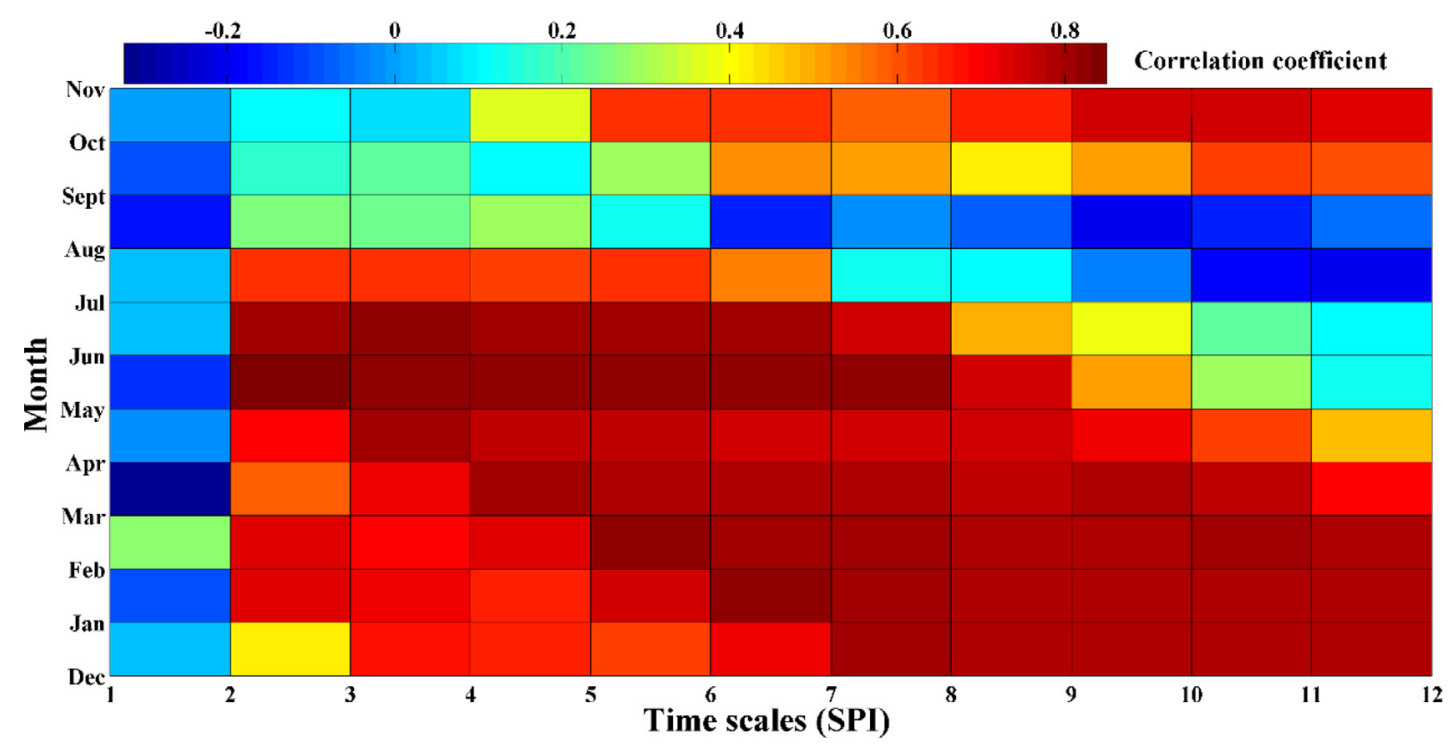

Fig. 6. The correlation coefficients between monthly PDSI and SPI series on various time scales in the whole basin. 

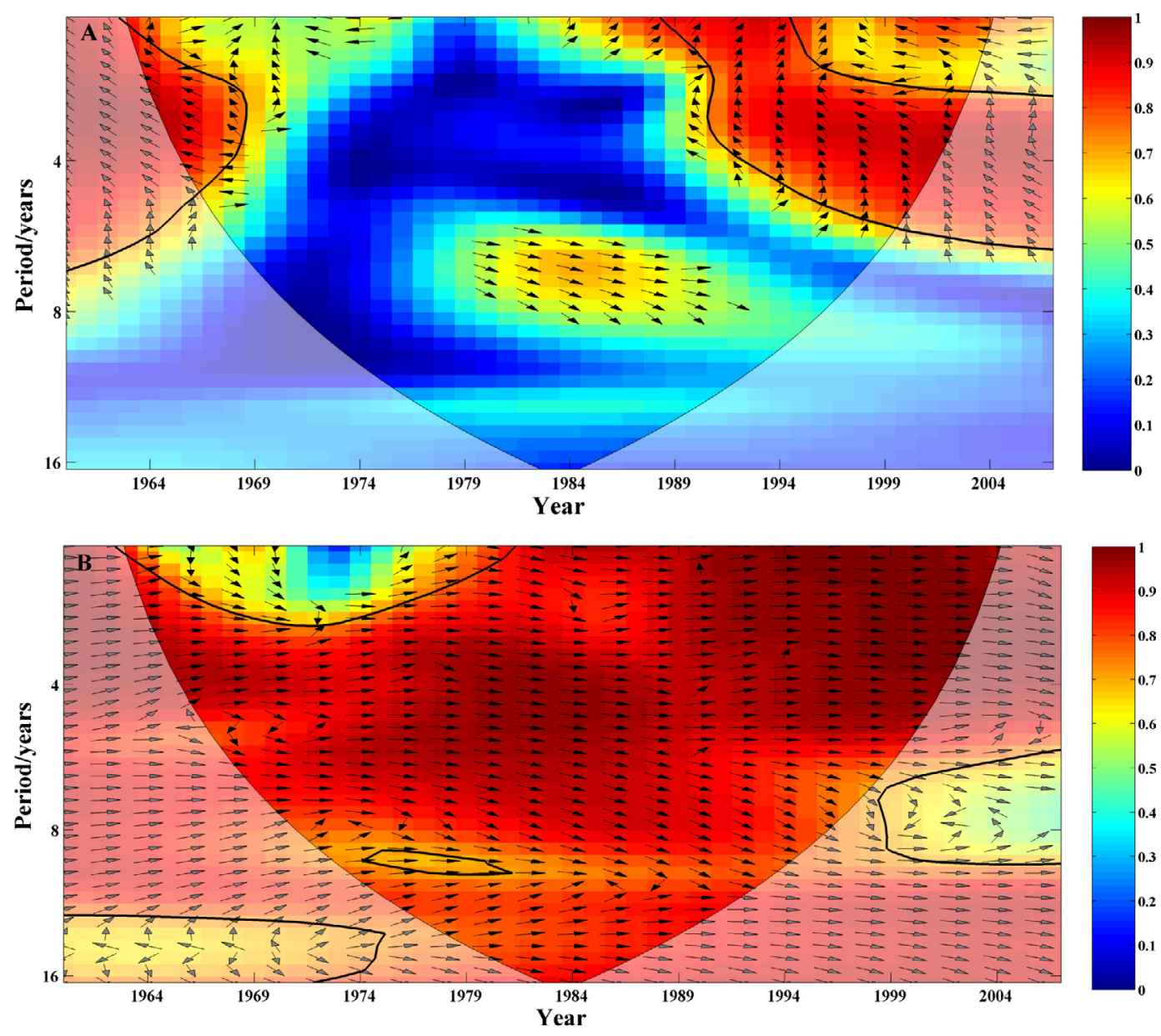

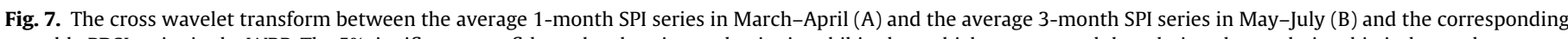

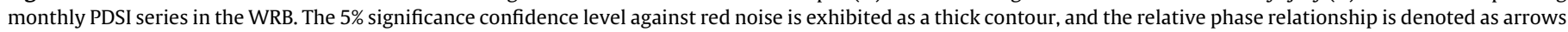
(with anti-phase pointing left, in-phase pointing right).

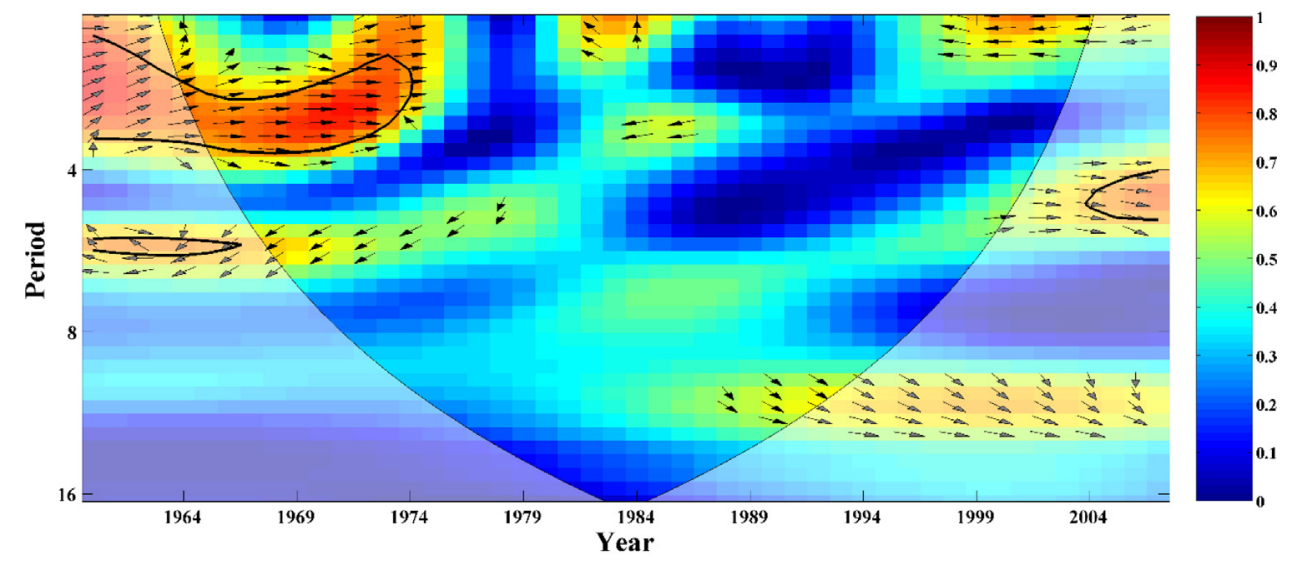

Fig. 8. The cross wavelet transform between annual actual evaporation in the WRB and average monthly AO values.

evaporation. Here, the cross wavelet analysis was used to analyze the correlation between annual actual evaporation which is calculated based on water balance and $\mathrm{AO}$ index in order to reveal the specific links between the lag time and large-scale atmospheric circulation. The cross wavelet transform between annual actual evaporation and average monthly AO values in 1960-2007 is shown in Fig. 8. Fig. 8 exhibits that actual evaporation in the WRB has a statistically significant positive correlation with AO with a 1-3 year period signal during 1960-1975 and has a slightly negative linkage with AO with a 5-6 period signal in the same period. Moreover, they also have both positive and negative relationship with different period signals during 1997-2007. In general, the influence of AO on the lag time is complex, which includes both positive and negative effects. Therefore, Fig. 8 further verifies that the large-scale atmospheric circulation has a strong effect on the lag time of agricultural drought responding to meteorological drought on a relatively long time scale. 
4.5. The correlation between the lag time and local underlying surfaces

As mentioned above, local underlying surfaces including soil type, vegetation cover and topography type could have a great effect on the lag time of agricultural drought responding to meteorological drought. It should be emphasized here that the parameter $(w)$ of the Fu' equation within the Budyko framework can reflect the influence of land surface characteristics. Therefore, the parameter $w$ was calculated in this study to reveal the specific correlation between the lag time and local underlying surfaces.

As outlined in Section 4.1, the average PDSI in the WRB after 1993 is much less than that before 1993. Hence, the entire period was divided into two sub-periods (1960-1993 and 1994-2007) for analysis. In order to investigate the detailed correlation between lag time and $w$ value, the lag time and $w$ values in the two subperiods in the three basins were computed, and the results are shown in Table 1. In general, the lag time of agricultural drought responding to meteorological drought has a negative correlation with parameter $w$. For example, in the basin above Zhangjiashan, the lag time increased with the decrease of corresponding $w$ value, whereas the contrary is true for the basin above Linjiacun and the whole basin. Li et al. (2013) reported that the basin-specific $w$ was linearly correlated with the long-term mean annual vegetation cover. For several decades, the soil and topography types can be regarded as unchanged factors in a specific basin. Hence, the changes in vegetation cover are the main local surface factor expected to directly affect $w$ variations, thus, influencing the lag time of agricultural drought responding to meteorological drought. It is worth mentioning that the water and soil conservation practices including building check dams, grass-planting, afforestation, and creation of level terraces have been carried out since 1960 to cope with the issue of severe soil loss. The increased evapotranspiration with more forests and grass may be a potential factor affecting the response of agricultural drought to meteorological drought. The areas of soil conservation practices in the WRB are presented in Table 2. It can be observed from Table 2 that the area of afforestation and grass-planting has increased quickly since 1990, which corresponds to the results that the lag time tends to be shorter after 1993 than that before 1993 in the basin above Linjiacun and the whole basin. The basin above Zhangjiashan, which is located in the most serious soil loss area, is characterized with

Table 1

The lag time and the $w$ values in the different periods in the three basins.

\begin{tabular}{llll}
\hline Station & Period & $w$ & Lag time \\
\hline Zhangjiashan & $1960-2007$ & 3.48 & 6 \\
\multirow{3}{*}{ Linjiacun } & $1960-1993$ & 3.53 & 3 \\
& $1994-2007$ & 3.34 & 7 \\
\multirow{2}{*}{ Huaxian } & $1960-2007$ & 3.09 & 5 \\
& $1960-1993$ & 2.96 & 5 \\
& $1994-2007$ & 3.61 & 1 \\
& $1960-2007$ & 3.25 & 6 \\
& $1960-1993$ & 3.21 & 6 \\
\hline
\end{tabular}

Table 2

Areas of soil conservation practices in the WRB.

\begin{tabular}{lccccr}
\hline \multirow{2}{*}{ Time } & \multicolumn{5}{l}{ Area of soil conservation practices $\left(\mathrm{km}^{2}\right)$} \\
\cline { 2 - 6 } & Level terrance & Afforestation & Grass-planting & Check dam & Total \\
\hline 1960 & 172 & 327 & 47 & 6 & 552 \\
1970 & 974 & 1309 & 193 & 24 & 2500 \\
1980 & 2918 & 3886 & 446 & 64 & 7314 \\
1990 & 4758 & 8468 & 2320 & 78 & 15624 \\
2000 & 9088 & 14924 & 3648 & 134 & 27794 \\
2006 & 11779 & 17157 & 4265 & 143 & 33344 \\
\hline
\end{tabular}

loose soil and concentrated rainstorm (Chen et al., 2008). Although the soil conservation practices in this region have been performed since 2000, the planted trees are still small. Hence, the forests and grass in the basin above Zhangjiashan tend to be degenerated. This is further confirmed by Chen et al. (2008) which indicated that the normalized difference vegetation index (NDVI) in the upper stream of the Jinghe River has a decreasing trend. Thus, being opposite to the basin above Linjiacun, the lag time in the basin above Zhangjiashan increased partly due to the decreasing evapotranspiration caused by decreasing vegetation cover.

\section{Conclusion and discussions}

It is of importance to investigate the lag time of agricultural drought responding to meteorological drought and the influencing factors, which not only helps to reveal drought process and regime, but also is useful for agricultural production and local water resources management. In this study, the heuristic segmentation method was applied to identify possible change points of annual PDSI and precipitation series. In addition, to reveal the possible influencing factors, the cross wavelet was utilized to reveal the links between agricultural drought and meteorological drought and the correlations between annual actual evaporation and average monthly AO values. The primary conclusions are as following:

Generally, the lag time of agricultural drought responding to meteorological drought in the WRB has a noticeably seasonal characteristic. Specifically, the lag time in summer is short (approximately 3 month), largely owing to the high-frequency rainfall and high soil moisture in this season. The lag time in autumn and winter is long, primarily resulting from the water stored in the soils during the preceding months. In general, the lag time in the basin above Linjiacun is shorter than that in the basin above Zhangjiashan mainly because of its larger slope. Given the different lag time in different basins, it is very necessary to consider about the usefulness of SPI with different time scales to monitor agricultural drought.

The average 3-month SPI series in May-July and the corresponding monthly PDSI series have a noticeably in-phase correlation at various time scales ranging from 1 to 16 years, suggesting the usefulness of 3-month SPI in detecting agricultural drought in WRB. Actual evaporation in the WRB has a statistically significant positive correlation with AO with a 1-3 year period signal in 1960-1975 and a slightly negative linkage with $\mathrm{AO}$ with a 5-6 period signal in the same period. Overall, the influence of $A O$ on the lag time is complex, which includes both positive and negative effects, indicating that the large-scale atmospheric circulation has a great effect on the lag time. In addition, the lag time of agricultural drought responding to meteorological drought has a negative correlation with parameter $w$, which is closely associated with the change in vegetation cover, implying that the vegetation cover in the WRB plays an important role in affecting the lag time of agricultural drought responding to meteorological drought. Therefore, both the wide-range atmospheric circulation and underlying conditions have a strong impact on the lag time.

In practice, the PDSI index used in this study cannot exactly reflect the actual conditions of local agricultural drought. However, we used PDSI to approximately characterize agricultural drought in the WRB, with an explicit purpose of revealing the response of agricultural drought to meteorological drought at the seasonal time scale and the influencing factors including large-scale atmospheric circulation and local landscape conditions. The findings acquired in this study further revealed the response of agricultural drought to meteorological drought and drought propagations, which lays a solid foundation of constructing agricultural drought warning system based on meteorological data, thus being helpful for local water 
resources management, economic development and agricultural practices.

It is very interesting to explore whether the findings of this study would remain in the future under the background of global warming, which could provide guidance for policy-makers in climate change mitigation and adaptation strategies. Hence, future studies will be performed by examining the agricultural drought to meteorological drought using the newly CMIP5 (Coupled Model Intercomparison Project Phase 5) climate model outputs under various emission scenarios.

\section{Acknowledgements}

This research was supported by the National Major Fundamental Research Program (2011CB403306-2), the National Natural Fund Major Research Plan (51190093), the Natural Science Foundation of China (51179148, 51179149, and 51309098), the Key Innovation Group of Science and Technology of Shaanxi (2012KCT-10), the Non-profit Industry Financial Program of MWR (201301039) and the China Scholarship Council. Sincere gratitude is extended to the editor and the anonymous reviewers for their professional comments and corrections, which greatly improved the presentation of the paper.

\section{References}

Beniston, M., Stephenson, D.B., 2004. Extreme climatic events and their evolution under changing climatic conditions. Global Planet. Change 44, 1-9.

Changnon, S.A., Easterling, W.E., 1989. Measuring drought impacts: the Illinois case. Water Resour. Bull. 25, 27-42.

Chen, C.C., Xie, G.D., Zhen, L., et al., 2008. Analysis of Jinghe watershed vegetation dynamics and evaluation of its relation to precipitation. Acta Ecol. Sin. 28 (3), 0925-0938.

Christensen, O.B., Christensen, J.H., 2004. Intensification of extreme European summer precipitation in a warmer climate. Global Planet. Change 44, 107-117.

Dai, A.G., Trenberth, K., Qian, T.T., 2004. A global dataset of Palmer Drought Severity Index for 1870-2002: Relationship with soil moisture and effects of surface warming. J. Hydrometeorol. 5, 1117-1130.

Dai, A.G., 2010. Drought under global warming: a review. Wiley Interdiscip. Rev.: Clim. Change 2, 45-65.

Dai, A.G., 2011. Characteristics and trends in various forms of the Palmer Drought Severity Index during 1900-2008. J. Geophys. Res. 116, 1-26, D12115.

Dracup, J.A., Lee, K.S., Paulson, J.E.G., 1980. On the definition of droughts. Water Resour. Res. 16 (2), 297-302.

Elfatih, A., Eltahir, B., Yeh, P.J.F., 1999. On the asymmetric response of aquifer water level to floods and droughts in Illinois. Water Resour. Res. 35, 1199-1217.

FAO, 1991. The Digitized Soil Map of the World (Release 1.0). Food and Agriculture Organization, Rome, Italy.

Fu, B.P., 1981. On the calculation of the evaporation from land surface. Scientia Atmospherica Sinica 5 (1), 23-31 (In Chinese).

Grinsted, A., Moore, J.C., Jevrejeva, S., 2004. Application of the cross wavelet transform and wavelet coherence to geophysical time series. Nonlinear Process. Geophys. 11, 561-566.

Guttman, N.B., Wallis, J.R., Hosking, J.R.M., 1992. Spatial comparability of the Palmer Drought Severity Index. Water Resour. Bull. 28, 1111-1119.

Huang, S.Z., Chang, J.X., Huang. Q, et al., 2014a. Spatio-temporal changes and frequency analysis of drought in the Wei River Basin, China. Water Resour. Manage. 28 (10), 3095-3110.
Huang, S.Z., Hou, B.B., Chang, J.X., et al., 2014b. Copulas-based probabilistic characterization of the combination of dry and wet conditions in the Guanzhong Plain. China J. Hydrol. 519, 3204-3213.

Hudgins, L., Friehe, C.A., Mayer, M.E., 1993. Wavelet transforms and atmospheric turbulence. Phys. Rev. Lett. 71, 3279-3282.

Hudgins, L., Huang, J.P., 1996. Bivariate wavelet analysis of Asia monsoon and ENSO. Adv. Atmos. Sci. 13 (3), 299-312.

Kao, S.C., Govindaraju, R.S., 2010. A copula-based joint deficit index for droughts. J. Hydrol. 380, 121-134.

Kunkel, K.E., 2003. North American trends in extreme precipitation. Nat. Hazards 29, 291-305.

Li, D., Pan, Cong, M., Z, et al., 2013. Vegetation control on water and energy balance within the Budyko framework. Water Resour. Res. 49 (2), 969-976.

Lobell, D.B., Burke, M.B., Tebaldi, C., et al., 2008. Prioritizing climate change adaptation needs for food security in 2030. Science 319 (5863), 607-610.

Logan, K.E., Brunsell, N.A., Jones, A.R., et al., 2010. Assessing spatiotemporal variability of drought in the U. S. central plains. J. Arid Environ. 74, 247-255.

McKee, T.B., Doesken, N.J., Kleist, J., 1993. The relationship of drought frequency and duration to time scales. In: Eighth Conference on Applied Climatology. Anaheim CA, pp. 179-184.

Medved-Cvikl, B., Ceglar, A., Kajfe-Bogataj, L., 2012. The response of hydrological droughts to climatic droughts at different time scales in Dravinja, Savinja and Krka Basins in Slovenia. BALWOIS, Ohrid, Republic of Macedonia.

Mishra, A.M., Singh, V.P., 2010. A review of drought concepts. J. Hydrol. 391, 202-216.

Mohammad, R.K., Majid, V., Amin, A., 2014. Drought monitoring using a Soil Wetness Deficit Index (SWDI) derived from MODIS satellite data. Agr. Water Manage. 132 37-45.

Palmer, W.C., 1965. Meteorological Drought, Rep. 45. U.S. Dept. of Commerce, Washington, D.C, pp. 58.

Pandey, R.P., Ramasastri, K.S., 2001. Relationship between the common climatic parameters and average drought frequency. Hydrol. Process. 15, 1019-1032.

Pedro, B.G., Plamen, C., Luís, A.N.A., et al., 2001. Scale invariance in the nonstationarty of human heart rate. Phys. Rev. Lett. 87 (16), 160815.

Tallaksen, L.M., Van Lanen, H.A.J., 2004. Hydrological drought: processes and estimation methods for streamflow and groundwater. In: Development in Water Sciences. Elsevier Science, Amsterdam, Netherlands, pp. 46-48.

Torrence, C., Compo, G.P., 1998. A practical guide to wavelet analysis. Bull. Am. Meteorol. Soc. 79, 61-78.

Wilhite, D.A., 2000. Drought: A Global Assessment. Routledge, New York.

Roy, S.E., Balling, J.R.C., 2004. Trends in extreme daily precipitation indices in India. Int. J. Climatol. 24, 457-466.

Roderick, M.L., Farquhar, G.D., 2011. A simple framework for relating variations in runoff to variations in climatic conditions and catchment properties. Water Resour. Res. 47 (12), W00G07.

Szalai, S., Szinell, C.S., Zoboki, J., 2000. Early Warning Systems for Drought Preparedness and Drought Management. World Meteorological Organization, Lisboa, pp. 182-199.

Van Lanen, H.A.J., Wanders, N., Tallaksen, L.M., et al., 2012. Hydrological drought across the world: impact of climate and physical catchment structure. Hydrol. Earth Syst. Sci. Discuss. 9, 12145-12192.

Van Loon, A.F., Van Huijgevoort, M.H.J., Van Lanen, H.A.J., 2012. Evaluation of drought propagation in an ensemble mean of large-scale hydrological models. Hydrol. Earth Syst. Sci. 16, 4057-4078.

Wang, D.B., Mohamad, H., Cai, X.M., et al., 2011. Climate change impact on meteorological, agricultural, and hydrological drought in central Illinois. Water Resour. Res. 47, 1-13, W09527.

Yang, D.W., Sun, F.B., Liu, Z.Y., et al., 2007. Analyzing spatial and temporal variability of annual water-energy balance in non-humid regions of China using the Budyko hypothesis. Water Resour. Res. 43 (4), W04426.

Yang, H.B., Yang, D.W., 2011. Derivation of climate elasticity of runoff to assess the effects of climate change on annual runoff. Water Resour. Res. 47 (7) W07526.

Zhang, B.Q., Wu, P.T., Zhao, X.N., et al., 2012. Drought variation trends in different subregions of the Chinese Loess Plateau over the past four decades. Agric. Water Manage. 115, 167-177. 